\title{
Homosociality in the Classical American Stag Film: Off-Screen,
}

\section{On-Screen.}

\author{
'Seduced by A. Prick, \\ Directed by Ima Cunt,
}

Photographed by R.U. Hard

The 1927 American stag film Wonders of the Unseen World, whose pruriently succinct credits I have borrowed for my epigraph, got it wrong. In fact Mr. Prick was the real director and Ms. Cunt only the star performer, while Mr. Hard, the state of whose arousal is solicitously queried throughout, was and is the spectator addressed. For it is no secret that there are many more cunts than pricks in front of the camera in this film, and in the American stag cinema in general--that distinctive corpus of approximately 2000 films of a total duration of perhaps 300 hours produced between 1915 and 1968 that is the subject of this essay ${ }^{1}$. It is equally without question that behind the camera

\footnotetext{
${ }^{1}$ This is my conservative estimate of the size of this corpus, extrapolated from the most reliable filmography available, in Di Lauro and Rabkin, 1976. The question arises of course of whether a group of films produced over more than half a century, encompassing both professional studio productions in $35 \mathrm{~mm}$ and their amateur $8 \mathrm{~mm}$ descendants, could constitute a "corpus" in any useful sense. However I insist on the coherence of this body of work, despite its obvious evolution over time, for three reasons: the continuity of its thematic and iconographic content, the continuity of its clandestine but commercial status throughout this period, and finally the finality of its termination by the emergence of explicit sexual cinema in the licit public marketplace around 1968.
} 
and in the audience there are pricks and only pricks. Not only are most of the anonymous male artists during the heyday of the stag fanatically focused on the female organs, but they also in most cases do everything in their power to avoid showing male organs, to keep those pleated flannel trousers on.

There is nothing surprising in this avoidance, for the stag filmmakers who supplied the lively clandestine market of itinerant projectionists and all-male audiences are anticipating that great American pop culture tradition of genital aphasia of the postwar era, shaped by censorship, yes, but also by shame and disavowal. This tradition would reach its zenith in the 1950s with Russ Meyer $^{2}$ and Playboy, which for the first two decades of its history meticulously banished not only Ima's cunt from its airbrushed photographic iconography, but more significantly all hints of the male body, especially the eyes and penises to which the Bunnies were addressing their 'R.U. Hard?'s.' Take Smart Alec (1953), for example, some say the 1953 apogee of the American stag tradition, a film that miraculously does not even acknowledge that the male protagonist (who is lithe, blond and tanned if you really look hard) actually has a penis, and fights as hard to avoid getting it in frame as squeamish leading lady Candy Barr struggles to avoid sucking it. This is what I still remember from my experience thirty years ago on first seeing this film with a rowdy group of college boys who, smothered by Barr's sixteen-year-old mammary amplitude, didn't seem to notice the hero's castration...but that's

\footnotetext{
${ }^{2}$ Russ Meyer may well be identified in popular memory with his films of the late1960s, but his first breakthrough hit The Immoral Mr. Teas, appeared in 1959.
} 
another story. ${ }^{3}$ Throughout Strictly Union (1917), the protagonist Mr. Hardpenis may well have had his personal reasons for keeping his voluminous overalls on, but the tenacious drapery of most of his peers, as well as the unceremoniousness of male disrobings when they do happen in the stag film corpus, whether off-screen (e.g. Inspiration [1945]) or via jump cuts (The Hypnotist [1931]; Fishin' [1941]), are part of the consistent pattern of denial.

At the same time, the general corpus of the American stag film demonstrates the obsession of patriarchal culture with the elusive Ms. Cunt, with 'figuring and measuring' the unknowable 'truth' of sex--making the female sex speak, as Linda Williams might put it (Williams, 1989) ${ }^{4}$--with penetrating women's bodies and their erotic pleasure. But stag films fail remarkably in this endeavour. Playmates (1956-58), in which a lit cylindrical light bulb is inserted in the protagonist's vagina, is both an extremist parody of this desperate search for truth and a demonstration of its futility. However, what these movies ultimately succeed in doing instead is illuminating both the fleshly pricks they try so hard to avoid showing, or show only incidentally, and the symbolic phallus--in short, masculinity. This is my objective in this essay, to demonstrate how the stag films, both on-screen and off-screen, are tenaciously engaged with the homosocial core of masculinity as constructed within American society, inextricably spread out over what Eve Kosofsky Sedgwick calls the 'homosocial continuum.' (Sedgwick, 1985)

${ }^{3}$ I tell this story, along with many others, in Waugh, 1996: 2-3.

${ }^{4}$ Williams treats classic stag films in Chapter 3 of this definitive monograph on heterosexual film pornography of the seventies and eighties, 'The Stag Film: Genital Show and Genital Event.' 
Only rarely does this question of masculinity erupt explicitly in the stag film corpus. For example, two films draw attention to the pattern elsewhere by their deployment of an exceptional trope: in the remarkably similar denouements of An Author's True Story [1933], and Goodyear ${ }^{5}$ [1950s], two worldly wise stag heroines pause and diddle thoughtfully with flaccid and spent pricks, shown unusually up close, as if to ask not only 'R.U. [No Longer] Hard?,' but also 'what is this that has caused so much narrative and social commotion?' The Goodyear performer even shakes her head--sadly? bemusedly?--as she looks at the unprepossessing organ. The cartoon Buried Treasure (1925) is the only other site of what I would call an overt interrogation of masculinity, availing itself exuberantly of the resources of animated metaphor and deconstruction. This nonphotographic [i.e. graphic and iconic, rather than indexical] 'western', with its penile swordfights and visual jokes about buggery, crab lice, impotence, castration and prostitution, is the only hint of the problematization of sex that Williams would diagnose in a much later corpus, seventies hardcore, the only anticipation of the screen-size blowups of monstrous detachable pricks in Deep Throat (Gerard Damiano, 1972) and its ilk. In the corpus of American stags made between 1915 and 1968, there are thus a few moments of explicit reflection among more than three hundred hours of unconscious masculinity on display in spite of itself.

I am not denying that some evidence of women's subjectivity also flickers against the grain of the stags. Across the screen divide come occasional glimpses of female subjectivity in different forms: pleasure (the rare unmistakeable female orgasm identified by diarist Glenway Wescott in a 1949

${ }^{5}$ Goodyear is unusually prophetic in its focus on condoms, hence the title. 
stag screening as 'the female finally lifting in a kind of continuous kiss of the entire body from head to foot,' [Wescott, 1990: 266]); camaraderie (especially with other women, e.g. nude bathing à trois in Getting His Goat [1923], but also with men, e.g. the extraordinarily congenial and natural conversation the skinny dipper in Fishin' has with her farmboy conquest); generous professionalism (the Nun's [1958] expert fingers irresistibly drawn back to the anus of her humping Fabian-haired lover); distraction (the most important thing the star of Kensey Report [sic, c. 1950] has on her mind at the end of her performance is to frantically brush off her flouncy black New Look cocktail skirt); and, yes, disgust (the buxom blonde with the heap of Betty Grable ringlets grimaces and wipes her face after an unforeseen ejaculation in The Dentist [c.1947]). Admittedly these films were presumably directed by men, and ultimately sutured within the framework of male subjectivity. But the spontaneous "natural" resonance of these gestures I have described, in relation to the self-conscious awkwardness of most of the nonprofessional performances throughout the stag corpus, gives them a behavioural authenticity that stands apart. But these instances, notwithstanding a certain revisionist identification with stag women by 'bad girl' feminists of the $1980 \mathrm{~s},{ }^{6}$ are idiosyncratic moments that seep almost by chance through the continuous fabric of male subjectivity.

Aside from these chance flickers of documentary 'truth' in this paradoxical, primitive, and innocent art form that seeks cunt and, as I will show, discovers prick, what do we learn then, directly but mostly indirectly, of

\footnotetext{
${ }^{6}$ Such refreshing rereadings of vintage heteroerotica first surfaced in F.A.C.T.
} Book Committee, 1986. 
men? The whole mosaic of underground erotic film and its spinoff genres does more than expose men's gazes and gestures, and even the occasional full-shot male body. It also exposes the spectrum of male sociality, the experience of having a penis (and being white) ${ }^{7}$ in the first two-thirds of the twentieth century. For in front of and behind the camera, on the screen and in the screening room, this spectrum radiates in all its ambiguities and over-determinedness, however hermetic, abstract, individualized, and displaced the narratives are. A. Prick lives in packs.

In the rest of this brief essay I would like to examine this spectrum of male homosociality that is the object, setting and vehicle of Mr. Prick's prolific and obsessive work. Or, I would like to lay bare, as John H. Gagnon and William Simon put it back in 1967 (the only social scientists to my knowledge to have studied the stags' subcultural milieu, no doubt aware that they were witnessing the swan song of the stag), the 'primary referent of the films in this instance [which] is in the area of homosocial reinforcement of masculinity and hence only indirectly a reinforcement of heterosexual commitments'(Gagnon and Simon, 1973). ${ }^{8}$

\footnotetext{
${ }^{7}$ Nothing is apparently known about the circulation of stag movies within African-American circuits, the occasional black character in the corpus notwithstanding (approximately a dozen black men or women appear in American stag films seen by the author).
}

8 The passage quoted is a slightly more detailed, updated version of an earlier description first published in TransAction Magazine in 1967 (July-August) and assembled in the same authors' 'Pornography--Raging Menace or Paper Tiger,' The Sexual Scene (New York: Aldine, 1970), p. 144. Gagnon and 
Let's start with the pack in front of the screen. In 1976, Al Di Lauro and Gerald Rabkin, the chief stag historians in a still sadly untrodden field, embellished our picture of this crowd in its North American variant, active from the interwar period through the fifties. Participant observers, it is implied, Di Lauro and Rabkin vividly evoked the small-town stag parties, Legion smokers and fraternity clubhouse parties with film programs run by furtive travelling projectionists carrying suitcases of reels (Di Lauro and Rabkin, 1976: 25, 54-57). Gertrud Koch has assembled the only slightly more bountiful documentation, mostly German, on the audience in Europe and Latin America, found chiefly on the brothel circuit and having an accessory relation to the trade in real flesh. (Koch, 1990: 17-29). ${ }^{9}$ These historical accounts emphasize

Simon offer astute observations about the audience scene and intervene politically in the debates about pornography at the height of the sexual revolution; but, like many empiricist social scientists, they are less astute when actually watching the screen (if they did so) and are guilty of observing that the stag film 'is rarely more than a simple catalogue of the limited sexual resources of the human body' (p. 144), a statement whose every adverb, adjective and noun can be demonstrated to be utterly wrong by screening the most basic selection of stag films.

9 Other than Koch, Williams, Gagnon and Simon, Di Lauro and Rabkin, and the original Kinsey research triumvirate, another principal source on the stag cinema is Arthur Knight and Hollis Alpert, 'The History of Sex in the Cinema', a feature that ran in Playboy from 1965 to January 1969; see esp. 'The Stag Film', Playboy, Vol. 14 No. 2 (November 1967), 154-58, 170-89; see also 
the interactive, collective nature of spectatorship in both Old World and New (the Americans' imagined dialogue runs 'Hey Joe, look at the jugs on that broad!' [Di Lauro and Rabkin, 1976: 25] while the German equivalent, less speculative, describes 'shouts, consoling voices, grunts, applause and encouraging cheers' [Kurt Tucholsky, cited in Moreck, 1956]). In fact, no direct quotes by participants are available from any continent, and to my knowledge no oral histories. The fragmentary evidence of both milieus is frustratingly nonspecific, unreliable, moralistic, and condescending. But what else is to be expected for any domain of popular culture, much less one whose preservation has been doubly whammied by both cultural stigma and illicit status?

Williams justly chides Di Lauro and Rabkin for their feminist-baiting indifference to the unequal economy of gender difference underlying the turn-on trade, and for their nostalgic sentimentalization of the homosocial vocation of the stag screenings (Williams, 1989: esp. 58, 92). I would agree with Williams about the fundamental insufficiency of any project to historicize in a non-feminist manner the commodification of sex and sexual representation that proliferated in Western culture both before and during the sexual revolution. Think about why so many male performers, unlike most of their leading ladies, wear masks and disguises, and how abject it must be to get fucked by a man wearing a mask (or absurd--the heroine of Inspiration

Waugh, 1996, chap. 4, "'(Oh Horror!) Those Filthy Photos": Illicit Photography and Film,' esp. pp. 309-22. A question: does it support my thesis about homosociality that most of the major literature on stag history has been written by male buddy teams? 
[1945] can't stop laughing at her partner's Groucho Marx glasses and mustache!).

But in fact Di Lauro and Rabkin's summary of the acculturation and initiation role of the group screenings, extrapolated from the findings of Gagnon and Simon, is itself quite unsentimental and to the point. They stress above all the tensions, anxieties, avoidance, and embarrassment of the group experience, the 'forced bravado of laughter and collective sexual banter,' and the obligation 'to prove to their fellows that they were worthy of participating in the stag ritual.' (Gagnon and Simon, 1973: 266). No wonder the enquiries about tumescence were à propos, as were the fast and furious intertitle jokes that knowingly revved up the bravado and banter and bandaged over the vulnerability of the male libido (culinary images were a favorite, e.g. over the fellatio trope in Strictly Union [1917] are the titles 'Going downtown for lunch' and 'Cocktail sauce'). And as for the bonhomie of men getting hard together, Di Lauro and Rabkin seem hardly sentimental at all since they are in denial about the whole thing. Sentimentality is something I myself may well be guilty of, however, for to me, as for many "objective" observers who lean towards the homo end of the homosocial spectrum, the collective rituals of male homosociality are blatantly and inescapably homoerotic (a truth the 'physique films' of the fifties and sixties succeeded in marketing, but we'll come back to that).

In getting together to collectively get aroused--if not off--at the spectacle of Ima Cunt, the stag spectators were reenacting some of the basic structural dynamics of the patriarchy, namely, the male exchange in women, in this case the exchange in fantasies and images of women. Those clubrooms were the scene, lubricated by alcohol and darkness, of what Sedgwick defines as homosocial desire, 'the affective or social force, the glue, even when its 
manifestation is hostility or hatred or something less emotively charged, that shapes an important relationship [between men]'. (Sedgwick, 1985: 2; see also 1-26). The screenings enabled all the affective infrastructure and institutional support for that desire, from rivalry, competition, and heckling to procuring, matchmaking and cheerleading, from tandem or serial sharing of women's bodies to their collective repudiation, from the mutual ego reinforcement that Gagnon and Simon identified as a main dynamic of the fraternal Elks Club settings, to the functions of instruction, mentorship and initiation that characterized the frathouse environment. (Gagnon and Simon, 1973: 266) Above all, the specularization of homosocial desire is in place, in the screening room, on the screen: men getting hard pretending not to watch men getting hard watching images of men getting hard watching or fucking women. It is interesting that $\mathrm{Dr}$. Kinsey, the pioneering sex researcher who dramatically revealed the homoerotic within the sliding scale of the homosocial (himself immortalized by the stags in both Kensey Report, a year or two after his 'Report', and Kinsey Report [c. 1960], a decade later), was intensely aware, as a collector himself, of stag movies as an element in the erotic socialization of American (white) men. But in the long list of individual and private erotic stimuli that Kinsey included in his questionnaires, he asked respondents about the use of the stag film as an object of arousal but apparently didn't think to ask them about the context of erotic stimulation, about the same-sex collective public sharing of these cine-heteroerotic stimuli. (Kinsey et al., 1948: 23, 65)

The prevailing assumption in the historical accounts, including Gagnon and Simon's, Di Lauro and Rabkin's, and Williams's, is that group membership was rigidly policed through peer conformity in the homosocial spectatorial setting, and proof of membership was required (at least in the North American 
milieu(1)(2) European and Latin American brothels, according to the skimpy anecdotal evidence available, would have been much more tolerant of diversity, with a price and room for every fetish and perversion that could pay, multiplexes before their time ${ }^{10}$ ). However, in retrospect, none of the authors carry their image of male stress and vulnerability to the point where it undermines their assumption of monolithically uniform masculinity. None allows for the traumatized silence I felt when I saw Smart Alec with my dormitory peers in 1968 and the queer difference I and others must have felt. Extrapolating back through the decades, it is impossible not to imagine that difference was not present in all of those classic all-male audiences. Not only difference but also dissemblance, the deceptive performance of belonging.

Significantly, the only positive firsthand vintage account of the straight stag experience that I have tracked down, one that diverges from the self-righteous dismissals quoted by Koch and the Americans, is by another complicit but objective queer, Glenway Wescott. This man of letters rapturously described in 1949 the hydraulics and poetics of the male and female genitals as they meet, the unattractiveness of the featured couples notwithstanding. (Wescott, 1990: 266) There is no dissemblance in his report, not only because he was writing in his diary, but also because he'd not seen the stag package at a semiprivate homosocial smoker. He'd seen it at a private gay men's party, an option increasingly viable for both straights and nonstraights during the postwar boom in home movie technology.

\footnotetext{
${ }^{10}$ See my discussion of the pansexual atmosphere of the pre-WWII European brothel sexual culture in Hard to Imagine, 285-322.
} 
What about homosociality on-screen? The screen, like a mirror, reflected many of the same dynamics unfolding in the screening room. In particular I am thinking of the significant proportion of films depicting homosocial behaviour in a literal way, for example, to name only ten, The Aviator (1932), The Bellhop (1936), Broadway Interlude (1931-33), Dr. Hardon's Injections (1936), Emergency Clinic (1950), Grocery Boy (1944), Merry Go Round (1950s), Mixed Relations (1921), Paris After Dark (1947) and While the Cat's Away (1950-55). In such films, men share women, men get off watching men with women, men help men with women, men supplant men with women, men procure women for men, etc. And I am not even referring here to the small corpus of films that show explicit homoerotic behaviours in the context of heterosexual relations, a feature of stag films much more common in Europe than in phobic America. I have discussed these films elsewhere in terms of both queer authorial participation in stag film production and, perhaps more important for this essay (in the absence of historical evidence of a queer American A. Prick), the inoculatory function and freak-show operation of queer discourses in homosocial culture. (Waugh, 1996: esp. 309-22). ${ }^{11}$ In other words, regardless of whether queers produced or performed, for the spectator who watches the sexual other perform, e.g. the drag queen in Surprise of a Knight (late 1920s) or the black male cocksucker in A Stiff Game (1930s), the meaning is 'I am not like that.' Complementary to my initial discussion of the homoerotic stags are the recent advances by such researchers as Jonathan Ned Katz and George Chauncey in the historicization of evolving and diverse

11 The corpus analyzed consists of about fifteen pre-World War II films, about ten European, five American, and one Cuban. 
conceptions of masculinity that prevailed in the period of the classical stags. In certain contexts, these conceptions, according to Chauncey, 'allowed... men to engage in casual sexual relations with other men, with boys, and, above all, with the fairies themselves without imagining that they themselves were abnormal.' (Katz, 1995; Chauncey, 1994: 65)

Perhaps the most interesting stag plots in respect to homosociality are those narrative triangles in which two male accomplices or rivals express their bonding through a joint female partner. In An Author's True Story (1933), a variation on the artist-and-muse formula, a tormented proto-Barton Fink writer conjures up, and then spies on, his girlfriend for inspiration. He catches her redhanded betraying him with a Valentino-type lover, but significantly lingers at the keyhole until their debauch is played out. Only then does he rush the guilty couple, pummel his exhausted nude rival into unconsciousness (or is it depletion... or submission?), and proceed to supplant the interloper in the heroine's embrace. The new couple is cushioned on the languorously spread out and very becoming body of the gigolo (who peeks once or twice, to get his own look at the acrobatics unfolding on his abdomen). The climax then images a threeway relation of intense intimacy and tactility, concluding as I've mentioned, with an unusual visual articulation of the finally softened penis. Who is getting off on (literally) whom?

Another example from the next decade, The Photographer: Fun and Frolic in the Studio (1940s), is curiously self-reflexive about both the homosocial triangle and a triangle of representation engaging the male imagemaker/spectator and the heterosexual performers. An excitable male photographer, fully clothed, is directing a porno shoot starring a seasoned Jean Harlow-type blonde and her butch and tattooed but somewhat passive male partner. The couple seem to need a lot of coaching, and much guidance, 
both verbal and manual, is provided by the metteur-en-scène, in between his fussy attention to the lights and camera. The blow job phase of the operation seems to require special attention on the part of the photographer, and his solicitous identification with the ministrations of the heroine is quite palpable. I wondered while watching whether this was a case of standard projection/transference or whether this film would turn out to be another homoerotic buried treasure. But no, the photographer finally declares, somewhat exaggeratedly, his own horniness and receives his share of 'Jean Harlow"s oral attention, but almost as an afterthought, without any disrobing. Here the triangle formula is all but explicitly built on the binary of opposing models of masculinity, including that of the artsy type fairy. Is the perfunctory final denouement, the "heterosexualization" of the photographer, added as an unconscious disavowal of the difference within masculinity that otherwise resonates from the frame?

A final triangular example, of the fifties this time, is equally 'perverse': the wife in While the Cat's Away entertains her lover in the wood-paneled family abode, but cleverly pushes him into the closet when her husband comes home unexpectedly (1) (1) horny, as it turns out. The lover ends up watching the married couple have sex from the closet vantage point, and two emphatic shots, including the final image of the film, show him standing masturbating through the half-open door (fully clothed, naturally). What is the object of this wanker's voyeuristic pleasure...and the object of the director/spectator's? And do they know? How to unentangle these complex circuits of desire, sight and performance played out by characters/performers and spectators/performers?--even putting aside the anachronistic reading that fin-de-siècle viewers should resist applying to the final title, but won't: 'I wonder if that guy ever got out of the closet?'! 
No doubt the old-fashioned class politics of the encounter between movie women and male spectators are less ambiguous than these unanswerable questions around the sexual politics of male-male desire. Between stag screen and stag audience, one discerns not only a narrative/visual match but also a political synchronicity. Departing from a monolithic view of masculinity, of $A$. Prick, requires us to investigate his class and ideological particularity. Gagnon and Simon define the class sensibility of the smoker audiences as 'upper lower and lower middle class' (boy-next-door Elks, remember, not elite Rotarians), and the frat boys may be thought to share some of this social positioning by virtue of student status (rather than their probable future class identification as managers, professionals, and owners). In any case, recurrently surfacing through all the ribaldry and innocence of the stags is a palpable but amorphous populist resentment. This sensibility crystallizes, not so much in the direct class references in the stags (although doctors, intellectuals, bankers, and bosses often come off rather badly) and not so much in ethnic/racial terms (although the demographic uniformity of the audience erupts occasionally in racist and xenophobic humour and stereotype, for example, the addition of racist jokes about Asian sexual anatomy and Asian-American social types in the American subtitles to the French Le Ménage du Madame Butterfly [sic; 1920]. This sensibility crystallizes most concretely in gender terms. It cannot be denied that detectable misogynist discourses inflect the more idealizing or fetishizing representations of Ms. Cunt. How else to account for the edgy eroticizations of the insatiable nympho (Strictly Union); the treacherous adulteress (Dr. Hardon's Injections [1936], While the Cat's Away); the duplicitous cockteaser, castrator and avenger (Getting His Goat); above all, in the character of the prostitute? 
The 'hooker' presides over the entire corpus of stags in a generalized way, inflected by the familiar hypocritical class-centric contempt for the working girl, since the female performers were undoubtedly assumed by the audience to be sexworkers--and most clearly often were as much, just as their inept male partners were assumed to be and were visibly amateurs. (In fact, pursuing this documentary reading, the stag corpus may well be the best visual ethnography of sexworkers in America during this period). Many of the performers were decades older and less trim than the prevailing ideal of the sixteen-year old Candy Barr, adding the complication of age to the misogynist economy at play around the sexworker.

On a literal level, the hooker is incarnated specifically in character types who exchange sex for money, not desire, in films from The Casting Couch (1924) to Artist's Model (1945) to The Payoff (1950s; the narrative hook for this item is the rent, as far as I can make out). Few literally drawn prostitute characters appear in the stag stories as such, but the recurring exchange of money and services implies that most female characters are candidates. This element of populist male blame that channels the stresses of masculinity awakened by the stag film setting, this social scapegoating attached to the attractive/repulsive lumpen femme fatale, is of course a familiar element in popular and high art of the period. But neither the arts nor the social sciences progressed much further than Kinsey, with his exemplary refusal to moralize and his conclusions that the mythology of prostitution was more significant than its actual operation, and that actual contact with female sexworkers by white American males was class-inflected (frequency inversely proportional to rising social/educational level). If Kinsey was right, and 'upper lower and lower middle class' American men were more exposed to prostitutes than their 'betters,' this would at least partly confirm why a class-homogeneous audience 
like the Elks or American Legion, situated within a gynephobic and erotophobic culture and focused on a narrative form descended from the punitive logic of the dirty joke, might fixate its transgression anxieties and guilt on the lumpen hooker character (just as reform movements and V.D. panics had done for a century). There is a sour flavour in the representation of these dozens of efficient and sportsmanlike workers in the stags--in the mocking intertitles and jokey endings that invite heckling, in the mechanical mise-en-scene of genitals and 'meat shots,' in the contempt for the seller but not the buyer, in the indifference of metteur-en-scène to the women's pleasure. Can one detect in these onscreen and offscreen dynamics an ancestor of the class resentment, and the embrace of obscenity and grossout as populist revolt, that Laura Kipnis has dissected so brilliantly in Hustler magazine of the seventies and eighties? (Kipnis, 1993) I'd bet on it, but this is clearly a subject for further research. ${ }^{12}$

I have left for last one small body of erotic films tangential to the stag film proper but very relevant to it: the 'physique' cinema, mail-order homoerotic films that came into being only as the stags were on their last legs after World War II. Here again the order of the day is difference and dissemblance (queer lust disguised as exercise films!) rather than the rambunctious honesty of the stags, and, rather than class resentment focused on the lumpen hooker, a kind

\footnotetext{
${ }^{12}$ One model for such research might be Theweleit, 1987, a fascinating historical analysis of the relation between class-based social anxiety and misogynist representations, a study of post-World War I German proto-fascist male culture and politics.
} 
of idealized class fetishism of proletarian muscle. (Waugh, 1996: 255-73) Not surprisingly, physique films don't care very much about Ima Cunt--at least not directly--and concern themselves overwhelmingly with A. Prick and R.U. Hard (though they are never allowed to show the penis except under clinging fabric, and only abs and pecs are hard).

In many ways the movies of Bruce, Bob and Dick (Bellas, Mizer, and Fontaine, respectively, major auteurs of the genre) shared the swaggering innocence and small-format, one-reel primitiveness of their predecessors, reinventing the voyeuristic cinematic gaze and narrative as they evolved. In other respects, fittingly, these mail-order posers and wrestlers have more in common, formally and contextually, with the burlesque teasers, the Betty Page leg art/fetish prancers, and other peripheral licit and semi-licit genres of their age. All were hiding behind legal, artistic, scientific, political, medical, and sports justifications--or playing with such justifications, working winkingly (and wankingly) within the law of their day. All had to maneuver within the gray border zones of the licit rather than the no-holds-barred underground of the stags. The price of licit status is of course very high, not only in terms of the posing straps which prevented the genital choreography that is the centerpiece of the stags, but also politically, in terms of self-hurting camouflages (the alibi of bodybuilding as a denial not only of eroticism but also of self) that place the physiques in a totally different category of illicitness from the stags' missionary-position conformity. The judicial record of producers and customers alike (the wily physique mogul Bob Mizer may have brushed off his run-ins with the law but collector Newton Arvin was destroyed $)^{13}$ are there to

\footnotetext{
${ }^{13}$ Newton Arvin (1900-1963), a Smith College professor and National Book Award winner, was allegedly at the center of a 'smut ring' broken up by the
} 
remind us of the physiques' outcast status. Both filmmakers and buyers were marked not only by the stigmas of sex and kitsch, but also by the ostracism and the enforced closet in the age of criminalized sodomy and witchhunts by police, psychiatrists, and politicians. Directors and audiences usually managed to surmount these problems with the humour and resilience of the oppressed. These films were not made for the Elks!

Nevertheless, like the stags, the physique films were made by men for men about men, and thus they too are about the specularization of masculinity, about the spectrum of homosociality. The physique films, although almost entirely merchandized to individual mail-order customers, addressed collective, interactive groups as much as they did furtive solo wankers: physique pioneer Dick Fontaine vividly recalls the raucous private parties in Manhattan lofts at the start of the fifties that were the testing ground for his own early work, (Fontaine, 1991) and Arvin's prosecution was wholly predicated at the end of the decade on his intent to 'exhibit' his collection to his friends.

Is there an iconographical overlap between the two sets of films? Only a few character types walk back and forth between the stags and the physiques (the odd bellhop, repairman, live-model artist, burglar, and Oriental[ist] potentate). The stags were never interested in prisoners, gladiators, sailors, bikers, athletes, bodybuilders and cowboys--farmboys maybe, but that's the heritage of earlier erotic folklore--and the physique artists were understandably never interested in doctors and sex researchers with

Massachusetts authorities in 1959. At issue was a collection of physique magazines, photos, and movies (Martin, 1994). 
flabby bodies and sedentary desk jobs. Any overlap resides mostly in the homosocial codes and formulae: rivalry and sharing, display and specularization, trickery and triangles, crescendo and release. And the logic of surrogacy, fetish and tongue-in-cheek coding, from frenzied wrestling as a knowing simulacrum of fucking to fun with spears and guns and boots, is of course unique to the Aesopian exigencies of working above ground but under the still Comstockian US Post Office.

The opposition between stags and physiques is neat, set by the glue of transgression: on the one hand, illicit films about licit desire and, on the other, licit films about illicit desire. Admittedly, during the pre-sexual revolution heyday of the stags, the Hays days of the Hollywood Production Code, the stags' specialty acts of adultery, prostitution, and sex--extramarital, nonreproductive, oral, female-initiated, interracial and group--were in fact officially illicit or 'deviant.' Yet they were unofficially bolstered by a patriarchal culture founded on the double standard of male promiscuity and female monogamy. Ironically, the physique movies' cult of All-American masculinist icons, boys next door--however illicit their coy orchestration of double meanings really was--seems on the surface the epitome of populist respectability, the overstated yearning of the pariah to belong. Were any of the stag genres and their grungy hetero spinoffs more abject and transgressive than these ballets of cleancut Marines and glistening jocks? Each corpus in fact engaged in dialogue with the other about precisely those fuzzy boundaries between the licit and the illicit, between the homoerotic and the homosocial. The stags could ultimately overlook the fuzziness in their anxious innocence, but the physique movies knew exactly was the problem was, and how to exploit it--and celebrate it.

Comparing, then, the stag corpus and its physique underbelly, one is 
overwhelmed by how much the iconographies of desire are differently determined by social status and audience infrastructure. But in fact the two genres were moving in similar directions in the fifties at the beginning of the sexual revolution, both poised nervously on the same homosocial continuum of desire. Both were also eagerly embracing new technologies, $16 \mathrm{~mm}, 8 \mathrm{~mm}$, and soon Super 8, and eventually that electronic panacea that was still a gleam in the producers' eyes in 1968, home video. Thanks to these technologies, both traditions were penetrating the domestic sphere, the physique films through above-ground mail order, the stag films through under-the-counter sales (the days of the itinerant projectionists were over). Both stags and physiques would also erupt in mutated form into the hardcore features of tenderloin theatrical circuits in the late sixties and early seventies--the entrenchment of homosocial male eroticism in the marketplace of the commoditized sexual revolution. These two interrelated corpuses, these mosaics of homosociality, these ethnographies of A. Prick and R.U. Hard, thus reentered the public patriarchal sphere together, arm in arm, pricks in hand.

\section{Acknowledgment}

For their support in this research, the author wishes to thank Oksana Dykyj, Chuck Kleinhans, Matthew Yokobosky, the Kinsey Institute for Research in Sex, Gender, and Reproduction, the Whitney Museum for American Art, Quebec's Fonds pour la Formation de Chercheurs et l'Aide à la Recherche, Concordia University, as well as the anonymous readers at Sexualities.

Note on Film and Video Sources

Archives The present author and all authors on classical stag cinema cited in this article have based their research primarily on the holdings of the archives 
of Indiana University's Kinsey Institute for Research in Sex, Gender, and Reproduction http://www.indiana.edu/ kinsey/; kinsey@indiana.edu) which has by far the most important collection of these materials (although recent reports are discouraging about the current accessibility and maintenance of the collection).

Further research was conducted by the author courtesy of the Whitney Museum of American Art, New York, in connection with a planned exhibition on classical underground erotic cinema in 1998, which was cancelled after an administrative shakeup (the whereabouts and provenance of the assembled exhibition materials are unknown).

San Francisco's Institute for the Advanced Study of Human Sexuality (iashs@ihot.com, http://www.iashs.edu/) boasts of a large vintage erotic film and video collection but the author has not verified its usefulness as a research resource. Prints of Playmates, The Photographer: Fun and Frolic in the Studio and one or two other titles are held by the Concordia University film archive.

Commercial video. Packages of classical stag films are available from several commercial video distributors in the U.S., including Movies Unlimited's useful basic collection of both hardcore and softcore materials under such titles as Stag Reels: 1920s-1930s, Flaming Flappers, Nudie Classics, Grindhouse Follies, etc. (cusserv@moviesunlimited.com; http://www.moviesunlimited.com ); and "Something Weird Video/The Picture Palace"( http://picpal.com ), which have several reels entitled "Stag Party" (not verified by the author). Movies Unlimited also offers several collections of homoerotic physique movies, such as anthologies of output from Bob Mizer's studio Athletic Model Guild with such titles as AMG: Fantasy Factory and Third Sex Cinema: Inside the A.M.G., etc. 
Works Cited

Chauncey, George (1994) Gay New York: Gender, Urban Culture, and the Making of the Gay Male World 1890-1940. New York: Basic Books.

Al Di Lauro, Al, and Rabkin, Gerald (1976) Dirty Movies: An Illustrated History of the Stag Film 1915-1970, with an introductory essay by Kenneth Tynan. New York and London: Chelsea House.

F.A.C.T. Book Committee (1986) Caught Looking: Feminism, Pornography and Censorship. New York: Caught Looking.

Fontaine, Dr. Richard E. Interview with author, June 1991.

Gagnon, John H. and Simon,William (1973) Sexual Conduct: The Social Sources of Human Sexuality. Chicago: Aldine.

Katz, Jonathan Ned (1995) The Invention of Heterosexuality. New York: E.P. Dutton.

Kinsey, Alfred C., Pomeroy, Wardell B. and Martin, Clyde E.(1948) Sexual Behavior in the Human Male. Philadelphia and London: W.B. Saunders Company.

Kipnis, Laura (1993) '(Male) Desire and (Female) Disgust: Reading Hustler', in Kipnis (ed.), On Sex, Capital, Gender, and Aesthetics. Minneapolis:

University of Minnesota Press.

Koch, Gertrud (1990) 'The Body's Shadow Realm', translated by Jan-Christopher Horak, Jump Cut 35: 17 - 29.

Martin, Robert K. (1994) 'Scandal at Smith', Radical Teacher 45(Winter): 4-8. Sedgwick, Eve Kosofsky (1985) Between Men: English Literature and Male Homosocial Desire. New York: Columbia University Press.

Moreck, Curt (1956) Sittengeschichte des Kinos. Cited in Koch (1990): 20. Theweleit, Klaus (1987) Male Fantasies. Volume 1: Women, Floods, Bodies, 
History, translated by Stephen Conway. Minneapolis: University of Minnesota Press.

Waugh, Thomas (1996) Hard to Imagine: Gay Male Eroticism in Photography and Film from their Beginnings to Stonewall. New York: Columbia University Press.

Wescott, Glenway (1990) Continual Lessons: The Journals of Glenway Wescott, 1937-1955, Robert Phelps with Jerry Rosco (ed.). New York: Farrar, Straus and Giroux.

Williams, Linda (1989) Hard Core: Power, Pleasure and the 'Frenzy of the Visible'. Berkeley and Los Angeles: University of California Press. 
Notes 